\title{
Editor's Note: The Choreographic Composite
}

In this Special Issue of Dance Research Journal, attention turns to "body parts," in particular the pelvis, feet, face, hips, legs, toes, and teeth. That we name discrete parts signals a range of scientific, aesthetic, and social investments in the topography of the body. Within the field of medicine, anatomical knowledge of each part serves to support the healthy functioning of the overall body; culturally variable standards of beauty are articulated in relation to the physical configuration of different parts; and as this special issue reveals, isolated body parts are inscribed by discourses of value, status, and power. In dance, scholars and artists have long reacted against the Cartesian mind/body duality through which the head dominates, and have proposed alternative conceptions through the idea of a "thinking body" (Todd 1937) or by privileging all of its parts in the creation and execution of movement practices. Some dance genres conceive the body as an organic whole that works to find a holistic connection between its various parts. For instance, somatic movement systems and contact improvisation come to mind as bodily practices that place little hierarchy on the organization of the body. Yet other forms highlight and prioritize localized areas that become sites of technical prowess and movement invention, such as the complex rhythmic footwork of vernacular tap and the spectacular finger tutting from hip-hop.

Several scholars have voiced concern, however, over the idea of a fragmented body. Feminist film scholar Annette Kuhn (1985) observes how pornographic representations of women typically compartmentalize the female body, thus reducing her to breasts, lips, or genitals, and dance scholar Brenda Dixon Gottschild (2003) offers a critique of how racialized conceptions of the feet, butt, skin, and hair have worked to essentialize and subjugate the black dancing body. Notably, one of the themes that runs through this special issue relates to how body parts engage frameworks of identity, specifically across lines of gender, sexuality, race, class, and nation. Most interestingly for dance, the various body parts do not exist in isolation, but engender a dynamic choreographic relationship to the rest of the body. As the various essays reveal, individual body parts can move in compliance or contradiction to the whole, and this composite dancing body offers potential to maintain, destabilize, and critique dominant social meanings.

In "The Parting Pelvis: Temporality, Sexuality, and Indian Womanhood in Chandralekha's Sharira (2001)," Royona Mitra invokes the pelvis as a place of female empowerment through its capacity to embrace sexuality and procreation. While the pelvis has often occupied a troubled position, particularly through the lens of critical race theory in relation to social couple dances, with the still pelvis of the Euro-American body distancing itself from the perceived mobility and virility of the African- or Latin-American dancing body, Mitra clearly reclaims the pelvis as a site of feminist investigation and celebration. Through a close analysis of Chandralekha's Sharira, a duet between a man and woman, Mitra details how the pelvis is put on display through the parting of the female dancer's legs, and how this action demands contemplation through the choreographic strategy of a slow and deliberate manipulation of time. This studied presentation of the female pelvis and its relationship to the male dancing body challenges heteronormative codes regarding Indian sexuality. 
In Margaret Morrison's “Tap and Teeth: Virtuosity and the Smile in the Films of Bill Robinson and Eleanor Powell," the focus turns to the corporeal relations between the smile and the feet within the representational framework of the Hollywood film musical. Morrison's study is particularly attentive to how the cinematic apparatus participates in the racialized, gendered, and class-based constructions of two tap dancing stars of the 1930s, Bill "Bojangles" Robinson and Eleanor Powell. On the one hand, the close-ups of their huge smiling faces indicate a willing submission to enact their prescribed subject positions of, in Robinson's case, the happy minstrel entertainer, and, in Powell's case, a passive feminine sexuality. Yet, on the other, Morrison asserts that the full body shots of the two performers enable them actively to showcase their tap dancing skill across registers of athleticism and virtuosity. Although Morrison concludes that this flash footwork is co-opted and commodified within dominant narratives of race, sex, and gender, this nevertheless remains an example of how one body part works in contrast to another.

Morrison's discussion of the smile effectively leads into my essay, "The Choreographic Interface: Dancing Facial Expression in Hip-Hop and Neo-Burlesque Striptease," which examines facial expression as a choreographic tool. I call upon Deleuze and Guattari's (1987) concept of "faciality" to consider how the smile of the Busby Berkeley chorus girl is semiotically coded as feminine and commodified. In response to this ideological ordering, I develop the idea of a "choreographic interface" to show how the dancing face enters into a choreographic relationship with other dancing faces and bodily territories, and this corporeal intertext acts as a site of meaning-construction. I exemplify this idea in motion through an analysis of a short hip-hop battle and a neo-burlesque striptease performance. Again, I pay close attention to the deployment of the smile, but in these cases its meanings are destabilized through the actions of other body parts or its interactions with other faces. In both examples, facial expression offers opportunity for social and political critique.

In Sarah W. Holmes's article, “The Pilates Pelvis: Racial Implications of the Immobile Hips," the return to the pelvis can be read in dialogue with Mitra's essay. Whereas Mitra proposes a redemptive reading of the pelvis, Holmes conceives it within the Pilates movement system as a strategy to normalize and invisibilize white supremacy. While Pilates has received much acclaim within the realms of kinesiology and sports science for its adoption of healthy anatomical principles, Holmes indicates that there is almost no consideration of its properties as a racially coded practice. She traces how its advocation of a still pelvis conforms to Euro-American ideals, and its commitment to lengthening the spine and stabilizing the hips developed historically as ballet and modern dancers turned to Pilates as a form of body conditioning; the aesthetic ideals of these bodies then shaped how Pilates was perceived. Most importantly, however, the racialized construction of the pelvis discursively disciplines the Pilates body, which Holmes describes through the movement principles and pedagogic language of two Pilates exercises.

Finally, Rebekah J. Kowal's essay “'Indian Ballerinas Toe Up': Maria Tallchief and Making Ballet 'American' in the Tribal Termination Era" considers how popular iconography of body parts aligns with narratives that underpin the Americanization of ballet and the assimilation of Native-American bodies into the American cultural landscape. Kowal focuses on ballerina Maria Tallchief and how the depiction of her face on popular magazines came to symbolize a "homegrown" American dancer, while images of her legs and toes, neatly encased within pink satin pointe shoes, signified technical virtuosity. As a dancer of Euro-American and Native-American heritage, Tallchief was represented as the "girl next door," which supported the desire to reposition ballet as a "native" art form in spite of its "foreign" roots. Yet the media interest in her Native-American heritage conveniently played into a problematic discourse of the assimilation of Native Americans in the tribal termination era.

I appreciate how all of the authors examine body parts within precise social and historical contexts to illuminate how they embody dynamic ideas and values. The notion of a choreographic composite 
might also be a useful strategy to think through the tensions and contradictions that exist across the dancing body. At the very least, this Special Issue shows the complex moves that each part contributes to the multiple articulations of the body overall.

Sherril Dodds

Guest Editor

\section{Note}

I would like to thank Mark Franko, Editor, for generously allowing me to edit this Special Issue of Dance Research Journal and for his willing mentorship throughout this process.

\section{Works Cited}

Gottschild, Brenda Dixon. 2003. The Black Dancing Body: A Geography from Coon to Cool. New York: Palgrave Macmillan.

Kuhn, Annette. 1985. The Power of the Image: Essays on Representation and Sexuality. London: Routledge.

Todd, Mabel Elsworth. 1937. The Thinking Body: A Study of the Balancing Forces of Dynamic Man. Gouldsboro, ME: Gestalt Journal Press. 